\title{
The essence of Urban form and its Relationship with Urban Aesthetics: A case from Rajshahi City, Bangladesh
}

\author{
Ferdous Farhana HUQ, Rajshahi University of Engineering \& Technology; Bangladesh \\ Imzamam UI Khan Shuvo, Rajshahi University of Engineering \& Technology; Bangladesh \\ Nidalia Islam, Bangladesh University of Engineering and Technology; Bangladesh
}

\begin{abstract}
The identity of a city is visibly recognized by observing its urban form. The development plans of the cities of Bangladesh address land use planning and ignore the aptness of urban form. As a result, the cities of Bangladesh are growing haphazardly and turning into an urban jungle rather than aesthetically pleasing habitable urban space. This study explores the intrinsic nature of the urban form of the major cities of Bangladesh as well as compares the urban form of major cities of Bangladesh with selected cities from around the world. This study conducts Physical Observation on building frontage, elevation, plinth level, footpath, doors and window pattern by employing transect method to acknowledge the character of the urban forms of the selected study area of Rajshahi city of Bangladesh. The findings of the study answer why the urban forms of the cities of Bangladesh look similar irrespective of cultural and geographical context. The findings shed lights on the weaknesses of current building codes regarding the compatibility of the design of the building elements as well as the relationship between building and street which leads to the degrade the urban aesthetics. Based on the findings some strategic and design solutions are provided with a view to improving the look of the city form.
\end{abstract}

\section{Keywords}

Urban form, Urban Aesthetics, Building façade, Building Elevation

\section{Introduction}

Urban morphology, urban form, and urban fabric are three terms that are highly interlinked with each other. According to Moudon (1997) urban morphology analyses the transformation of a city from its birth to its present state by identifying and dissecting its components. When it comes to the talk of the city's components, the first term comes is the 'physical form' of a city. Several researchers in their study have confirmed that a city can be read and studied by analyzing its physical form (Moudon 1997; Lynch. K 1959; Levy.A, 1999; Lu.S et.al, 2019). Whereas Dempsey.N et al. (N.D) have clearly mentioned that a city's physical characteristic hence physical form is officially termed as 'Urban form'. On the other hand according to Levy. A (1999), 'urban form' signifies the form of 'urban fabric'. Many recent works have disclosed different dimensions of urban fabric (Thompson \& Newman 2018, Muller, 2004, Newman and Kenworthy 1999, Newman and Kenworthy 2016). Based on their work the urban fabric can be summarized as a large fabric of urban form that 
portrays the essence of physical characteristics of a city. Therefore, the Urban form is the smallest unit of studying urban fabric as well as urban morphology. Dempsey et.al (n.d) in their study have mentioned density, buildings, layout, , and transport infrastructure as the major five elements of urban form, other researchers have generally address four fundamental elements of urban form which are buildings, open space, plots and streets (Moudon.V.A 1997 , Levy.A 1999). Kevin Lynch (1960) in this book discussed the effects of paths, edges, districts, nodes and landmarks on developing the image of the city. Urban aesthetics highly depends on the successful design of physical characteristics or urban form. Qualities of urban form are determined by the qualities of its fundamental elements and quality of urban form influences the human perception and visual complexity (Boeing, 2018). urban aesthetics is highly co-related with 'good visual complexity'. Good visual complexity depends on variety in buildings types, design details, street furniture, signage, human activity, light and shadow, textural details of street trees and urban open spaces. If the design becomes too predictable and controlled, the visual complexity becomes lost. Very few, similar, predictable, or too disordered to be comprehensible urban design produces poor visual complexity. Therefore the elements of urban forms have to be designed by maintaining a balance between order and disorder with unity and variety (Clifton et al. 2008, Elsheshtawy 1997; Gunawardena et al. 2015; Ewing and Clemente 2013; Boeing 2018).

This study focuses on understanding the tangible built environment of Rajshahi city from the perspectives of Urban aesthetics and finds out the influence of the modification of built forms on urban aesthetics.

\section{Study Area}

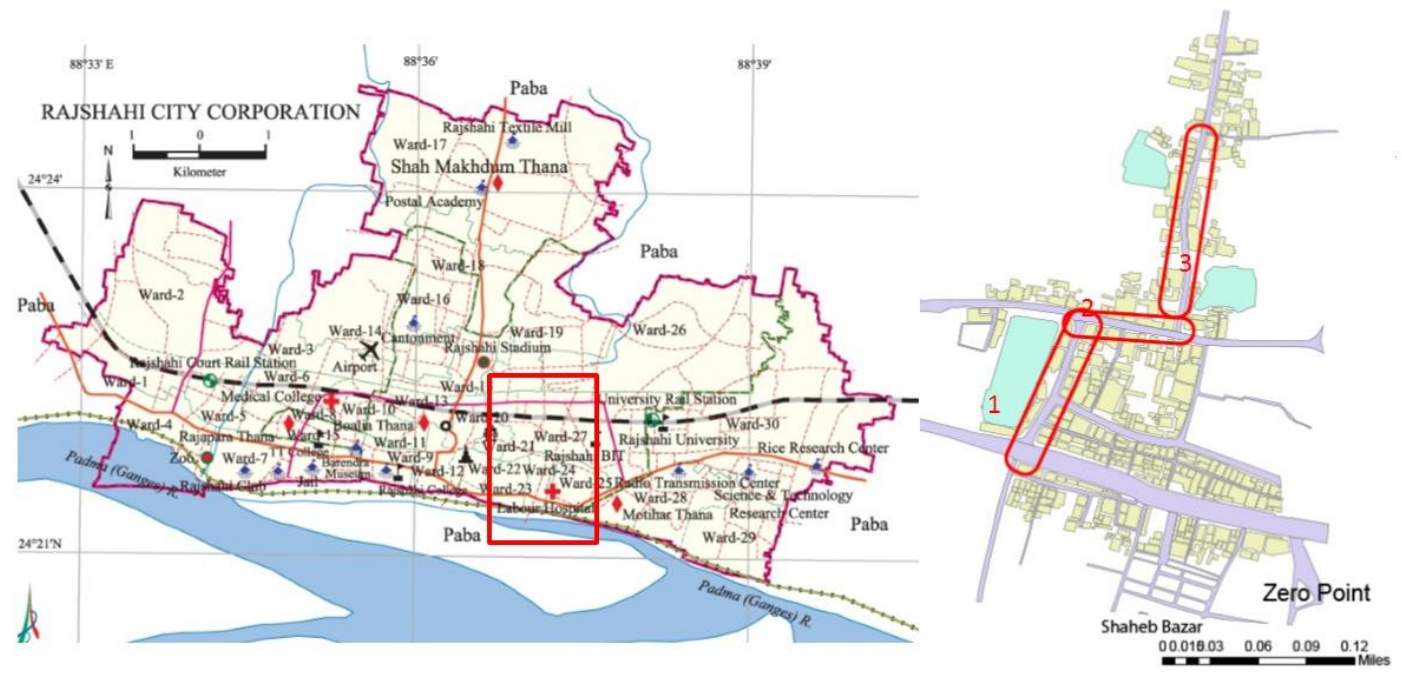

Figure 1 Map of the Research Area

Source 1 Author's preparations from Rajshahi Detailed Area Plan (2004-2024)

The study has been conducted at Malopara area located at the heart of Rajshahi which is one of the fast developing cities of Bangladesh. Three roads from Malopara named (1) MoniChootr, (2) Malopara road and (3) Malopara to Mohila college roads are studied for this research. These three roads have some unique buildings dated since $19^{\text {th }}$ to the $20^{\text {th }}$ century 
which makes this area different from other areas in terms of urban form as well as urban aesthetics ( Field Survey, 2018). formsFor the study, three roads of Malopara has been chosen. On these three roads, many types of uses are found. The lengths of the three roads are $0.14 \mathrm{~km}, 0.09 \mathrm{~km}$, and $0.41 \mathrm{~km}$ respectively. The total length of the study area is 0.64 kilometer.

\section{Method of the Study}

The method of the research is inspired from the method suggested by Lamas (1993) to understand the city by studying its elements i.e. ground, parcel, buildings, block, façade, vegetation, streets, squares, courtyards, monument, street furniture and larger structures (Lamas 1993 in Monteiro, n.d; Barbosa et.al, n.d). This research chooses Buildings, façade, ground, and street to study as these elements are the most relevant aspects to examine in the study area. To examine, the selected elements of urban forms direct observation method is used. A checklist was prepared to collect the basic information of the buildings. Transect method was applied where selected streets were divided into transects to classify the typical elements of each section (Watson, Plattus, \& Shibley, 2004). Three roads were mapped and characterized on the transect map. The panoramic survey was conducted where the photographic panorama of the study area was created to produce a detailed picture of the site (Anderson, 1978). The color, texture, materials, door and window pattern of the buildings were observed and noted as a part of studying the façade of the buildings. Building elevation survey was conducted to identify the elevation of the streetside buildings of the study area as building elevation is considered to be a significant component that explains urban form. Along with buildings elevation, Building's plinth elevation and footpath elevation were drawn by following a similar method. The data collected from the direct observation and field survey were visualized by using AutoCAD and 3d Sketch up the software to develop the findings of the research.

\section{Findings and Discussions}

\subsection{Visual Complexity}

The significant finding from three transects of three roads presents the dominance of are mixed-use building, blocked footpath, incoherent shop banner, haphazard electric wire, unmatched window pattern, different plinth level, irrelevant building shape, variety in building height and frontage, unmatched color and materials, few unique character door, window, veranda pattern, unique old buildings, broken dustbin and haphazard electrical wire. Visual complexity depends on the unity in the variety of the mentioned elements (Clifton, 2008, Boeing, 2018). The visual complexity of these roads is found to be high due to the lack of order developed by the construction of the modern building by not considering the design and pattern of neighboring buildings. The new-fashioned typical buildings are destroying the unique and traditional character developed by the old buildings in the study area. Mixed-use buildings in the study area have shops at the ground floor which follow various types of the pattern of their shapes, size, front material, nameplate color and nameplate size which degrade the aesthetics of the area. In a residential area, buildings are different in size, plinth level, height, color, texture, nameplates, door, and windows which 

area.
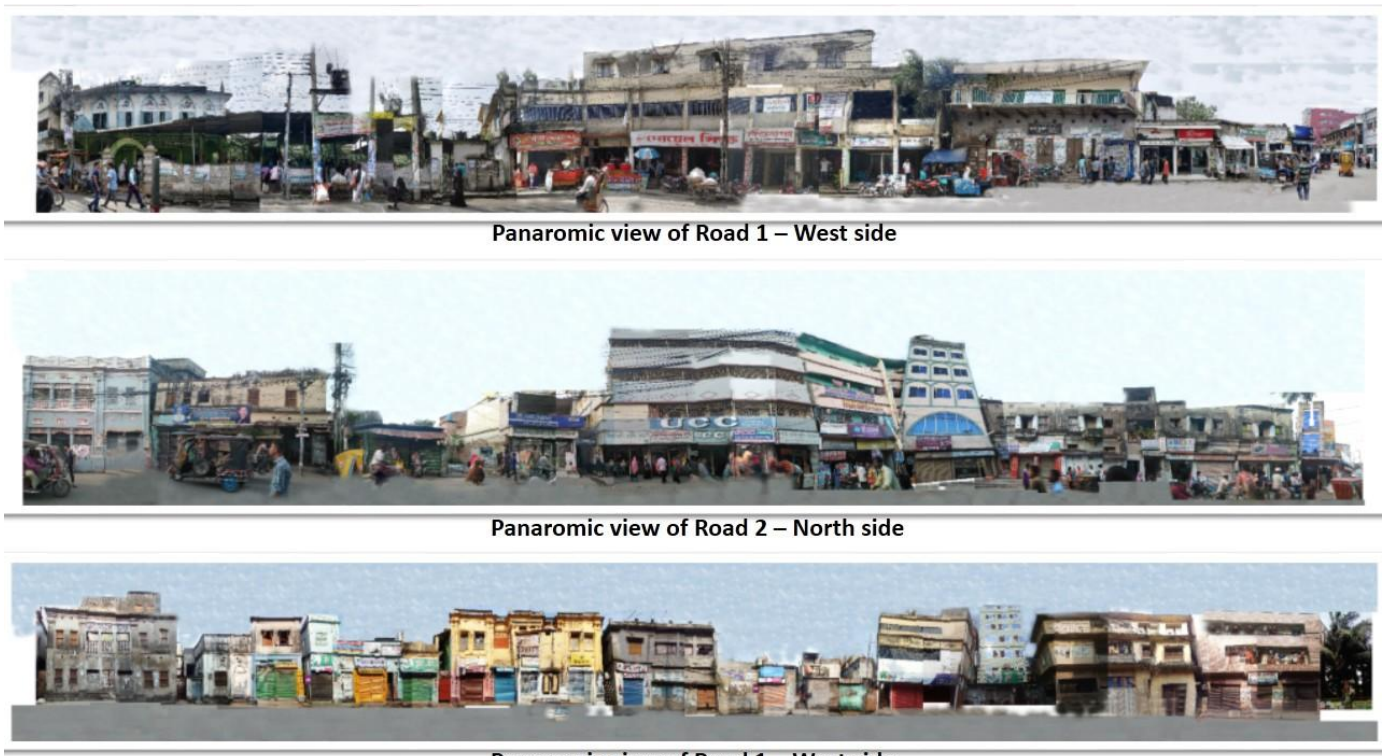

Panaromic view of Road 1 - West side

Figure 2 Panoramic Analysis of Research area

Source 2 Field Survey, 2018

\subsection{Façade Scenario}

The study area has many old, traditional style historic buildings which form a unique character in the area. But this character is being ruined due to the unconscious development trend. Findings from panoramic analysis approve the findings generated from transect analysis. The panoramic analysis focused on observing the color, texture, materials, plinth level, door, window, and veranda pattern. The panorama of First Street shows the ununiformity on the veranda and shop banner in terms of color and width. Panorama of the second street shows different plinth level of buildings which disturbs the image of the urban form by damaging the edge. The harmony of the building frontage is ruined due to not maintaining the unity in terms of color, texture and window pattern in buildings. According to the third panorama, shops uses different colored gates. Frontage material of the building is different and many buildings are identified using tiles in frontage which violates the unity in urban form hence destroys the urban aesthetics. Some building is found that has no plaster or broken plaster in the facade. Many buildings use different types of veranda and window pattern which has no harmony with the neighboring buildings (Figure 2).

Building Elevation Analysis of the streets suggests that most of the buildings of the study areas are one to three-story buildings. Few 4 to 5 storied buildings have been observed in the study area which is new buildings. Placement of high rise new modern buildings alongside single to double story old traditional buildings without maintaining the color, material and design harmony disturbs the look of the urban form at some points of the street. 
Table 1: Gate and door pattern analysis of the study area

\begin{tabular}{|l|l|l|}
\hline Road 1_Moni Chottor & Road 2_Malopara
\end{tabular}

Source: Prepared by Author

Table 2: Window pattern analysis of the study area

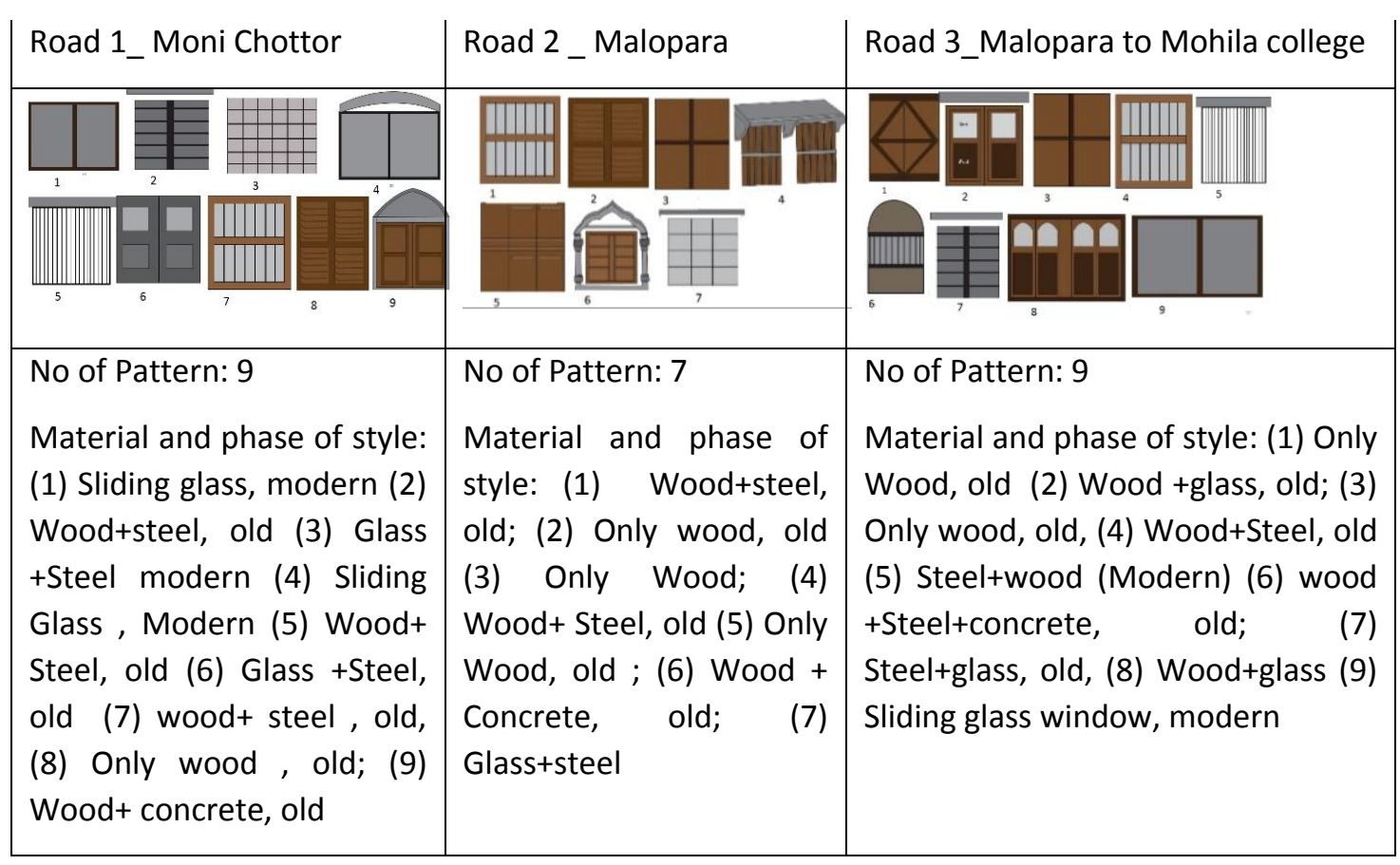


Remarks: In most of the buildings windows are made with a combination of wood, steel, and glass following traditional window pattern. New buildings are using sliding window made with steel and glass. Window pattern of this study area is found to be unique and modern buildings should be guided to use windows inspired by the design and materials from the old buildings of the study area.

\section{Source: Prepared by Author}

\subsection{Footpath and Plinth Level Analysis}

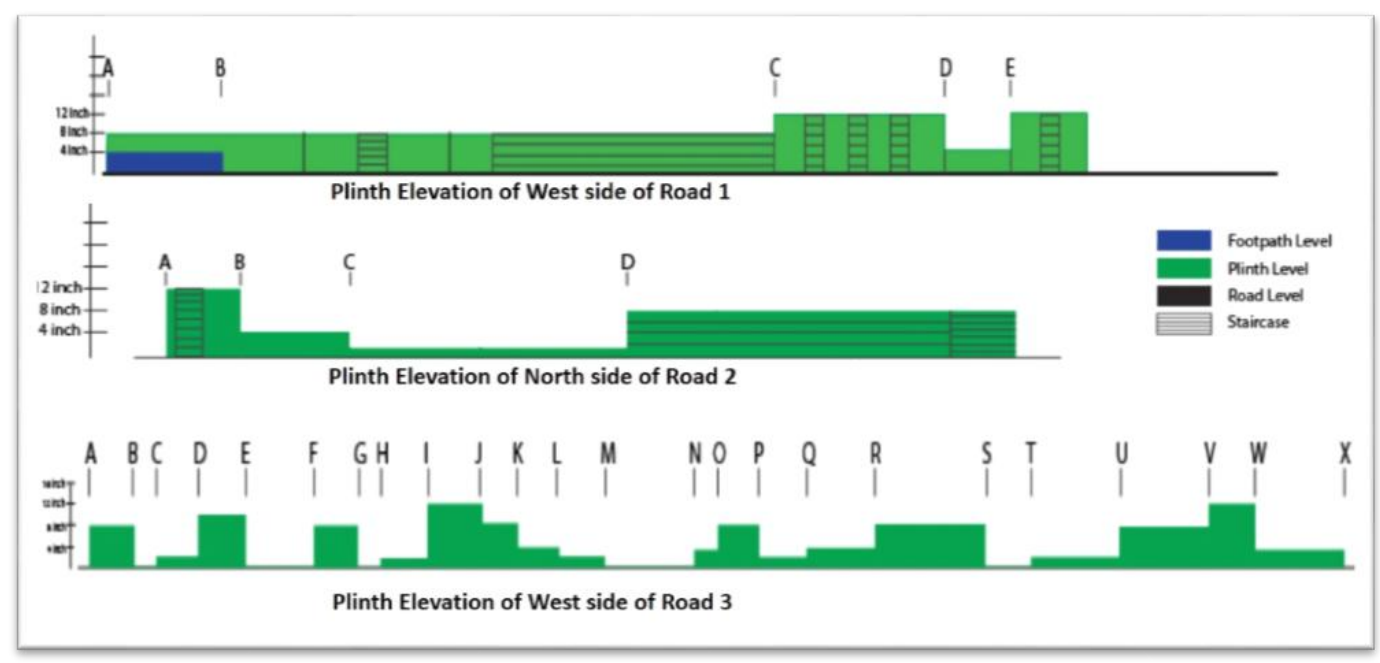

Figure 3 Plinth Level Analysis

Source 3 Field Survey, 2018

Footpath exists only from $A$ to $B$ of road 1 with an elevation of 4 inches from road level. Plinth level elevation is 8 inch from $A$ to $C, 12$ inches from $C$ to $D, 4$ inches from $D$ to $E$ and again become 12 inches from $E$ to rest of the road. On the second road, a great variation of plinth level from 2 inches to 12 inches has been noticed. An extreme variation of plinth level elevation is observed at road 3 where elevation varies from 0 inches to 12 inches. There exist no footpath exists in road 2 and road 3. People use stairs to reach plinth level from road level in road 1 and 2 . Such variation of plinth level not only destroys unity and harmony in the design of façade but also damages the aesthetics of urban streetscape (Figure 3 ).

\section{Conclusions:}

Research findings show the existing trend of streetscape development in Rajshahi city completely ignores the harmony, unity, and complexity of urban form. It is evident that the unique antique streetscape of Rajshahi city is under threat due to the ad-hoc development. To preserve the elegance and grace of this beautiful city we need to introduce some design guidelines for front façade at streetscape level. The guidelines should be able to give user full freedom to use a variety of materials and spatial planning freedom as well as regulate the new development to preserve the unique character of a street. To maintain the basic characteristic of streetscape- plinth height, building elevation, color, materials, scale, and proportion should be introduced to establish the order of urban form. Heritage corridor or streetscape preservation is very common worldwide. In the developed world, design architects, conservation architects, and planners work in a team to prepare a guideline for 
areas with unique characteristic and heritage building to prevent random development. This research strongly suggests introducing policy guideline based on the context of the particular area to preserve the beauty and classical aesthetic order of Rajshahi city. Rajshahi City Corporation needs to work on its disordered visual complexity incorporating Architects, Urban planners to establish the harmony of the streetscape.

\section{References}

Anderson, Hugh. (1978) "Panoramic Photography as a Survey Tool", http://www.hugh360.co.uk/measurement/photographic-intersection/panoramicphotography-as-a-survey-tool/

Barbosa, Eliana Rosa de Queiroz; Patrícia Capanema Alvares Fernandes; Tú, Nguyen Thanh (n.d) "URBAN MORPHOLOGY IN THE SOUTH - SPONTANEOUS AND INDUCED FORM", Global Development Network - working paper series Urbanization and Development: Delving Deeper into the Nexus.

Barros, Ana Paula; Martinez, Luis Miguel; Viegas, Jose Manuel (2017) "How urban form promotes walkability?", Transportation Research Procedia, Vol. 27 (September).

Boeing, Geoff (2018) "Measuring the Complexity of Urban Form and Design", Urban Design International, Vol. 23 No. 4 (October).

Bruno, Giuliana (2007) The Aesthetics of Human Environments, Peterborough, Canada, Broadview Press.

Celik, Deniz; Aciksoz, Sebahat (2017) "Urban aesthetic and urban landscape design guides: A Case study of Bartin, Turkey", Journal of Environmental Biology, Vol. 38 No. 5 (September).

Clifton, Kelly., Ewing, Reid., Knaap, Gerrit-Jan., \& Song, Yan (2008) "Quantitative analysis of urban form", Journal of Urbanism, 1(1), 17-45 (May).

Dempsey, Nicola; Brown Caroline; Raman, Shibu; Porta Sergio; Jenks, Mike; Jones, Colin; Bramley, Glen (2008) "Elements of Urban Form”, Oxford, UK, Springer.

Elsheshtawy, Y. (1997). "Urban Complexity. Journal of Architectural and Planning Research", Vol.14 No.04

Ewing, Reid; Clemente, Otto (2013). Measuring urban design. Washington, DC: Island Press, Washington, DC

Field Survey (2018) "Field survey conducted to identify the door window pattern, building elevation, plinth level elevation, panoramic view of Malopara area, Rajshahi"

Gracia-Domenech, Sergio (2015) "Urban Aesthetics and Social Function of Actual Public Space: A Desirable Balance", Theoretical and Empirical Research in Urban Management, Vol. 10 No. 4 (November).

Gunawardena, G. M. W. L.; Kubota, Yoichi; Fukahori, Kiyotaka (2015) "Visual Complexity Analysis Using Taxonomic Diagrams of Figures and Backgrounds in Japanese Residential Streetscapes", Urban Studies Research, Vol.2015 (September) 
Kashem, Md. Shakil Bin; Chowdhury, Tufayel Ahmed; Majumder, Joydip; Rahman, Md. Asif (2009) "Quantifying Urban form: A Case Study of Rajshahi City", Journal of Bangladesh Institute of Planners, Vol. 2 (December).

Levy, Albert (1999) "Urban morphology and the problem of the modern urban fabric: some questions for research", Urban Morphology, Vol. 3 No. 2 (July).

Lu, Shiwei; Huang, Yaping; Shi, Chaoyang; Yang, Xiping (2019) "Exploring the Associations between Urban Form and Neighborhood Vibrancy: A Case Study of Chengdu", China, International Journal of Geo-Information, Vol. 8 No. 4 (April).

Lynch, Kevin (1990) The Image of The City, Cambridge, Massachusetts, and London, England, Massachusetts Institute of Technology.

Monteiro, Evandro.Z (n.d) "Urban forms in diagrams", 21st International Seminar on Urban Form: Our common future in Urban Morphology

Moudon, Anne Vernez (1997) "Urban morphology as an emerging interdisciplinary field", Urban Morphology, Vol. 1 (March).

Muller, Peter.O (1886) “Chapter 3 Transportation and urban form - stages in the spatial evolution of the American metropolis" GEOGRAPHY OF URBAN TRANSPORTATION, United States

Newman, P. and Kosonen, L. and Kenworthy, J (2016) "Theory of urban fabrics: Planning the walking, transit/public transport and automobile/motor car cities for reduced car dependency", Town Planning Review, Vol 87 No 4

Newman, P., Kenworthy, J (1999) "Sustainability and Cities: Overcoming Automobile Dependence", Island Press, Washington, DC.

Özarslan, Dr. Nuray (2003) "Understanding The Historic City", Existics, Vol. 65 No. 391/392/393 (May).

Rezafar, Azadeh; Turk, Sevkiye Sence (2018) “Urban design factors involved in the aesthetic assessment of newly built environments and their incorporation into legislation: The Case of Istanbul", Urbani Izziv, Vol. 29 No. 2 (October).

Sharma, Shashikant Nishant (2014) "Urban Forms in Planning and Design", International Journal of Research, Vol. 1 No. 1 (February).

Shibley, Robert G., Plattus, Alan J., Watson, Donald (2003) "Time-Saver Standards for Urban Design", McGraw-Hill Companies

Thompson, Giles; Newman, Peter (2018) "Urban fabrics and urban metabolism - from sustainable to regenerative cities", Resources, Conservation and Recycling, Vol. 132 (May).

Turk, Ali (2014) "Historical Urban Fabric of Isparta City, Its Problems, Solution Offers, and Sustainable Urban Development", Journal of Engineering Sciences and Design, Vol. 2 No. 2.

Verdi, Laura (2014) "Aesthetics in urban space: architecture and art for sustainable cities", Social Space Journal (July). 